\title{
Historical perspectives of The American Association for Thoracic Surgery: David J. Sugarbaker
}

\author{
David A. Harris, MD, ${ }^{a}$ and Christine L. Lau, MD, MBA ${ }^{\mathrm{b}}$
}

David John Sugarbaker, the 94th president of The American Association for Thoracic Surgery (AATS), was born and raised in Jefferson City, Missouri. His mother, Geneva, was a nurse who used to encourage him to "Just be yourself; everyone else is taken." David was the eighth child in a family of 10, and by the time of his birth, David's father, Everett D. Sugarbaker, was well established in his practice as the first surgical oncologist west of the Mississippi. As the son of a surgeon, Sugarbaker was afforded unique insights, practical skills, and valuable opportunities in the world of surgery from a very young age. He remembers fondly assisting his father in the operating room, in the clinic, and in research pursuits in tumor biology. Aside from teaching the basic principles of surgery, when the time came his father provided critical mentorship about how to approach his career, how to run a surgical practice, and how to establish a new surgical division. Sugarbaker attended Wheaton College in Illinois, where he studied biology and philosophy, and he studied medicine at Cornell University Medical College in New York. He graduated at the top of his class as a member of the Alpha Omega Alpha Society and was inspired to pursue a career in surgery by his father and 2 older brothers, Everett V. and Paul Sugarbaker, who both became prominent surgeons. In 1979, 2 weeks before starting his surgical internship, Sugarbaker married Linda Sterk (Figure 1), and in the ensuing 35 years they have raised a family of 6 children, Rena, David, Deborah, Peter, Nathanael, and Evert.

Dr John Mannick, chief of surgery at the Peter Bent Brigham Hospital in Boston, selected Sugarbaker for general surgical residency in 1979 and has served as one of Sugarbaker's most influential mentors throughout his career. Sugarbaker's interest in general thoracic surgery began during a 2-year research fellowship in the Harvard Medical School's Thorndyke Laboratory, where he studied benign esophageal disease. In 1986, he completed his general surgical residency. Surveying the field at the time, Sugarbaker noted that many

\footnotetext{
From the Division of General Surgery, ${ }^{\text {a }}$ Brigham and Women's Hospital, Harvard Medical School, Boston, Mass; and the Division of Cardiothoracic Surgery, ${ }^{\mathrm{b}}$ University of Virginia Medical Center, University of Virginia School of Medicine, Charlottesville, Va.

Disclosures: Authors have nothing to disclose with regard to commercial support.

Received for publication July 7, 2014; accepted for publication July 13, 2014; available ahead of print Sept 17, 2014.

Address for reprints: Christine L. Lau, MD, MBA, PO Box 800679, Charlottesville, VA 22908-0679 (E-mail: cl12y@virginia.edu).

J Thorac Cardiovasc Surg 2015;150:1-3

$0022-5223 / \$ 36.00$

Copyright (c) 2015 by The American Association for Thoracic Surgery

http://dx.doi.org/10.1016/j.jtcvs.2014.07.018
}

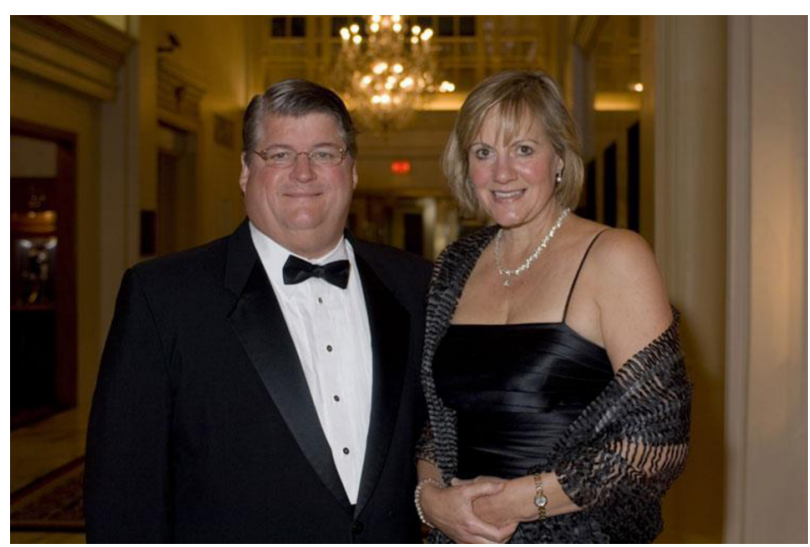

FIGURE 1. Dr and Mrs Sugarbaker.

leaders in esophageal surgery were trained in cardiothoracic surgery. So, with Mannick's encouragement, he completed a 2-year residency at the Toronto General Hospital, the only dedicated general thoracic surgery training program in North America at the time. Sugarbaker was privileged to train with Drs Joel Cooper (84th AATS president), F. Griffith Pearson (70th AATS president), Robert Ginsburg, Ronald Baird, and G. Alec Patterson (90th AATS president) and spent 1 year each in both thoracic surgery and cardiac surgery. After his specialty training, Sugarbaker returned to Boston, where, at the age of 35 years, he was appointed chief of the newly formed division of thoracic surgery at Brigham and Women's Hospital, which was the first dedicated general thoracic surgery division in the United States. In 1992, Sugarbaker developed the first general thoracic surgical training track in the United States, which he considers one of his most important accomplishments in cardiothoracic surgery. He has trained more than 80 residents, including $50 \%$ women and minorities, and has placed nearly two thirds of his graduates into academic positions (Figure 2).

During his tenure, Sugarbaker established numerous thoracic surgical programs in both oncology and transplantation, but he is probably best known for the development of a surgery-based multimodality treatment program for malignant pleural mesothelioma and as a champion for extrapleural pneumonectomy. Situated in New England, which has a rich tradition in the ship-building industry and a high concentration of asbestos-related lung disease, the division received numerous referrals for patients with asbestos-related lung cancers, including malignant pleural mesothelioma, in the 1980s and 1990s. At that time, surgical resection of the pleura, first performed by Irving Sarot in the 20th century for the treatment of tuberculosis, was 


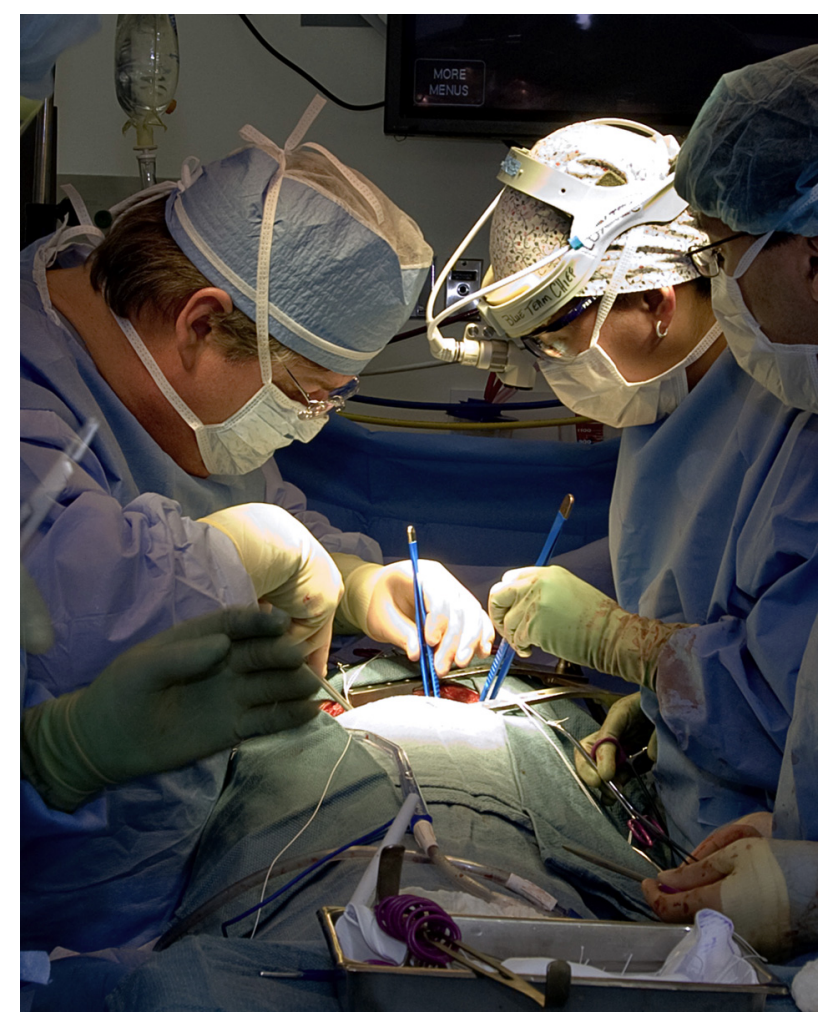

FIGURE 2. Dr Sugarbaker with one of his chief residents at the Brigham and Women's Hospital.

associated with a $20 \%$ to $40 \%$ operative mortality. ${ }^{1}$ Building on the expertise of the pathology department under Dr Joseph "Mack" Corson, he began to address the treatment of malignant mesothelioma, beginning with refinement of surgical resection. He sought advice from his father on how to fine tune his approach building on the standard for treating any solid tumor, establishing a safe and reliable surgical resection. In the case of mesothelioma, in which it is difficult to achieve an R0 resection, there must be subsequent therapy to address micrometastatic disease at the surgical margins, the presence of which Sugarbaker found to be the primary obstacle to extended survival. Sugarbaker has devoted more than 20 years to developing techniques for treatment of malignant pleural mesothelioma.

The first decade of Sugarbaker's career was devoted to adapting the 2 surgical procedures by which a pleural tumor could be resected, pleurectomy with decortication and extrapleural pneumonectomy. He credits complete diaphragmatic and pericardial resection with reconstruction and control of perioperative morbidity as the 2 most important improvements that have brought the operative mortality associated with extrapleural pneumonectomy to a nadir of $3.8 \% .^{2-5}$ The second decade of his career focused on the development and use of hyperthermic intraoperative chemotherapy to address the primary barrier to prolonged survival in malignant pleural mesothelioma, local recurrence. After identifying a population of patients with a low risk of local recurrence on the basis of histology, tumor burden, and absence of anemia, he was able to show that hyperthermic intraoperative chemotherapy with cisplatin doubled the time to local recurrence and prolonged survival. ${ }^{6}$

Sugarbaker founded the International Mesothelioma Program, which provides not only state-of-the-art therapy for mesothelioma and funding for mesothelioma research but also psychologic, spiritual, and practical support for family members as they confront this disease. The International Mesothelioma Program maintains the patient data registry for patients with mesothelioma, one of the largest in the world. Sugarbaker's academic story, however, does not end in Boston. Shortly after completing his term as AATS president in 2014, Sugarbaker accepted a position at Baylor St Lukes Medical Center in Houston to direct the new Lung Institute at the Baylor College of Medicine.

Sugarbaker became a member of the AATS in 1995, was appointed to the council in 2002, served as treasurer from 2007 to 2011, and served as the Association's 94th president in 2013 and 2014. Sugarbaker's presidential address, "Clarity of Purpose and Focused Attention: The Essence of Excellence," discussed the concept of excellence and how it relates to the practice of surgery. He addressed 3 main issues:

1. The essence of excellence. How is excellence defined and achieved? He noted the importance of singularity of purpose and purpose in the moment in identifying excellence.

2. The erosion of excellence. He noted that excellence in surgery is under attack. Unprecedented levels of daily disruptions erode our ability to identify and hold on to purpose and to focus our attention on that purpose. We need to take strong countermeasures to maintain clarity of purpose.

3. How can we inspire excellence in others and continue to strive for excellence in ourselves? He emphasized that we need to exclude unrelated thoughts, use repeated practice such as muscle memory for rote actions, and express situational awareness in the moment to maintain focus while excluding external distractions.

Sugarbaker ended his address with a very personal example of what he considered the essence of excellence. It was the story of Sugarbaker's father, who built a laboratory in the garage behind their family home in the mid 20th century to study the biology of tumor metastases in rats. The elder Sugarbaker maintained 3 tumor lines in his rat colony to study metastases, which led to his seminal work published in 1952 in the journal Cancer, "The Organ Selectivity of Experimentally Induced Metastases in Rats." Everett Sugarbaker's work continues to be referenced today and is recognized as a foundational contribution to the understanding of metastatic disease. Sugarbaker's story of his father's essence of excellence exemplified his premise that to achieve excellence in one's field, a singularity of 
purpose and focused attention are prerequisite to making progress. One needs to formulate a clear purpose, stabilize the workplace culture, and maintain focused attention to achieve excellence, and Sugarbaker and his father remain role models for us all to follow.

\section{References}

1. Sarot IA. Extrapleural pneumonectomy and pleurectomy in pulmonary tuberculosis. Thorax. 1949;4:173-223.

2. Sugarbaker DJ, Mentzer SJ, Strauss G. Extrapleural pneumonectomy in the treatment of malignant pleural mesothelioma. Ann Thorac Surg. 1992;54:941-6.

3. Sugarbaker DJ, Strauss GM, Lynch TJ, Richards W, Mentzer SJ, Lee TH, et al. Node status has prognostic significance in the multimodality therapy of diffuse, malignant mesothelioma. J Clin Oncol. 1993;11:1172-8.
4. Sugarbaker DJ, Flores RM, Jaklitsch MT, Richards WG, Strauss GM, Corson JM et al. Resection margins, extrapleural nodal status, and cell type determine postoperative long-term survival in trimodality therapy of malignant pleural mesothelioma: results in 183 patients. J Thorac Cardiovasc Surg. 1999;117:54-63; discussion 63-5.

5. Sugarbaker DJ, Jaklitsch MT, Bueno R, Richards W, Lukanich J, Mentzer SJ, et al. Prevention, early detection, and management of complications after 328 consecutive extra pleural pneumonectomies. J Thorac Cardiovasc Surg. 2004; 128:138-46.

6. Sugarbaker DJ, Gill RR, Yeap BY, Wolf AS, DaSilva MC, Baldini EH, et al. Hyperthermic intraoperative pleural cisplatin chemotherapy extends interval to recurrence and survival among low-risk patients with malignant pleural mesothelioma undergoing surgical macroscopic complete resection. J Thorac Cardiovasc Surg. 2013;145:955-63.

7. Sugarbaker ED. The organ selectivity of experimentally induced metastases in rats. Cancer. 1952;5:606-12. 